\title{
RELATO RIO
}

\section{EGRÉGIA CONGREGAÇÃO}

1. Cumprindo preceito regimental, tenho a honra de apresentar a essa doutíssima Congregação o relatório das atividade didáticas e administrativas verificadas no ano letivo findo.

\section{CORPO DOCENTE}

A Faculdade de Direito, neste ano de 1963, dispõe, para os vinte e três cargos de professôres catedráticos, que integram o seu quadro, de dezesseis titulares.

As cadeiras vagas estão sendo ocupadas por um Catedrático In. terino, Professor José Munhoz de Mello, Direito Constitucional do $2 .^{\circ}$ ano; três Professôres de Ensino Superior, Rubens Requião, Direito Comercial, do $3 .^{\circ}$ ano, Alcides Munhoz Neto, Direito Penal do $2 .^{\circ}$ ano e José Petrelli Gastaldi, Economia Política do 1. ${ }^{\circ}$ ano; um Professor Contratado, Gaspar Luiz Lacerda Pinto, na cadeira de Direito Civil do 5. ${ }^{\circ}$ ano; um Catedrático acumulando mais uma cadeira, Prof. José Ro. drigues Vieira Neto na cadeira de Direito Civil do $4 .^{\circ}$ ano; e um Instrutor de Ensino Superior designado pelo egrégio Conselho Técnico Administrativo para a cadeira de Direito Internacional Privado, do $5 .^{\circ}$ ano, Prof. Euclides de Queiroz Mesquita.

\section{PROFESSÔRES AUSENTES}

Permaneceu, durante o corrente ano, à disposição do Ministério da Educação e Cultura o Professor Humberto Grande, e o Professor Omar Gonçalves da Motta, catedrático de Direito do Trabalho, foi nomeado para o Corpo Permanente da Escola Superior de Guerra, por decreto do Exmo Sr. Presidente da República.

\section{CONTRATAÇÃO DE INSTRUTORES}

Foi renovado, no presente ano, o contrato do Instrutor Bel. René Ariel Dotti e, na vaga do Prof. Milton Tesserolli, foi contratado - Bel. Ruy Corrêa Lopes, designado pelo Conselho Técnico Administrativo para reger a cadeira de Introdução à Ciência do Direito. 


\section{LICENÇAS}

Gozaram licenças: especial de 6 mêses, o Professor Oscar Maitins Gomes; para tratamento de saúde, por três mêses, o Professor Laertes de Macedo Munhoz; e para tratamento de interêsse, durante todo o ano, o Instrutor Milton Tesserolli, da cadeira de Direito Romano.

\section{APOSENTADORIA}

A $10^{\circ}$ de setembro deixou o exercício de suas funções o Profes. sor Oscar Martins Gomes, em virtude de haver atingido o limite de idade, para desempenho de cargo público.

\section{FALECIMENTOS}

Tivemos a lamentar os falecimentos dos Professôres Oscar José De Plácido e Silva e Joaquim Penido Monteiro, homenageados pòstumamente pelo egrégio Conselho Técnico Administrativo e pela colenda Congregação, em sessões de 8 e 18 de fevereiro, do corrente ano, respectivamnte.

\section{CONCURSOS}

\section{a) - Cátedra de Direito Comercial}

Em virtude da ausência do Prof. Hernani Estrella, da Faculda. de de Direito do Rio Grande do Sul, integrante da respectiva Banca Examinadora, deixou de realizar-se o concurso para o preenchimentc de uma das Cadeiras de Direito Comercial, em que se achava inscrito, como candidato único, o Prof. Rubens Requião.

\section{b) - Livre-docência de Direito Civil.}

Com início no dia 21 de outubro, perante a Banca Examinado. ra, composta dos Professôres Armando Dias de Azevedo, da Faculdade de Direito da Universidade do Rio Grande do Sul, Washington de Barros Monteiro, da Faculdade de Direito da Universidade de São Paulo, José Hosken de Novais, da Faculdade Estadual de Londrina, Altino Portugal Soares Pereira e José Rodrigues Vieira Netto, desta Faculdade, foi realizado o concurso para a Livre-docência da Cadeira de Direito Civil, com a aprovação dos candidatos, Professôres José Lamartine Corrêa de Oliveira Lyra, Euclides de Queiroz Mesquita e Gaspar Luiz Lacerda Pinto, segundo a classificação por êles alcançada.

\section{c) - Inscrições}

No prazo legal, inscreveram-se para os concursos de Livredocência da cadeira de Ciência das Fianças os Bacharéis José Ribamar Gaspar Ferreira e Egas Rosa Sampaio, e para a cadeira de Direito Comercial o Bel. Luiz Silva e Albuquerque. 


\section{CONFERENCIAS}

a) Sob os auspícios da Reitoria da Universidade e desta Faculdade, proferiu conferência, no Auditório da Reitoria, em tôrno de seu anteprojeto de Código Penal, no dia 31 de outubro, o eminente Ministro Nelson Hungria.

b) A convite do Instituto Latino Americano de Criminologia, proferiu notável conferência na Faculdade de Direito da Universidade de São Paulo, subordinada ao tema - "O êrro de Direito e o êrro de fato", em face do anteprojeto de Código Penal", o eminente Professor Alcides Munhoz Neto.

c) Convidados pelo Instituto dos Advogados do Paraná e Ordem dos Advogados do Brasil, Seção dêste Estado, pronunciaram conferências abordando vários aspectos do anteprojeto de Código Penal, os Professôres Laertes de Macedo Munhoz, Ildefonso Marques e Alcides Munhoz Neto, e do anteprojeto de Código Civil os eminentes Professôres Altino Portugal Soares Pereira e José Rodrigues Vieira Neto.

d) Ainda sôbre o nôvo anteprojeto de Código Penal proferiu conferência nesta Faculdade o ilustre Professor Doutor Cesar Salgado.

e) A convite do Instituto Brasileiro de Direito Processual Civil proferiu aplaudida conferência na Faculdade de Direito da Universidade de São Paulo, sob tema de sua especialidade, o eminente Professor Egas Dirceu Moniz de Aragão.

\section{PUblicaÇÃo de LIVRO}

Foi recebido com alto júbilo pelos corpos docente e discente da Faculdade a publicação do livro "Introdução ao Direito Internacional Público", pelo ilustrado Professor Nelson Ferreira da Luz, Catedrático de Direito Internacional Público, havendo a Congregação em sessão de 7.11.63, mandado consignar em ata, por proposta do Professor Ary Florencio Guimarães, um voto de regosijo e de congratulação, pelo auspicioso fato.

\section{ESCRITÓRIO MODÊLO}

Orientado pelo advogado Rogério Fagundes, contratado pela Reitoria, funcionou regularmente o escritório de assistência judiciária desta Faculdade, ainda em regime experimental, mas já com apreciável rendimento, sendo de esperar para o próximo ano resultados mais proveitosos, com base na experiência adquirida.

Cumpre destacar, como realização de maior vulto, a obtenção de ordem de habeas-corpus, no egrégio Supremo Tribunal Federal, em grau de recurso. 


\section{ESCOLA TÉCNICA DE COMÉRCIO}

Com matrícula superior a 500 alunos, dos quais 125 colaram grau como técnicos de contabilidade e encerrando seu movimento financeiro com superavit, a Escola Técnica de Comércio anexa a esta Faculdade, cumpriu auspiciosamente mais uma etapa de suas fecundas realizações.

\section{FUNCIONALISMO}

Não sofreu alteração o quadro de funcionários, que está a exigir a nomeação ou contratação de novos elementos, por ser insuficiente o número dos atuais, para fazer frente ao constante crescimento do serviço.

\section{CONGREGAÇÃO}

Durante o ano letivo de 1963, a Congregação da Faculdade realizou 6 reuniões ordinárias e uma extraordinária, no dia 26 do corrente, em homenagem ao ilustre Prof. Doutor Oscar Martins Gomes, que foi saudado, pelo eminente Prof. Doutor Laertes de Macedo Munhoz, bem como pelo acadêmico Luiz Carlos Meinert, Presidente do Centro Acadêmico "Hugo Simas".

\section{CONSELHO TÉCNICO ADMINISTRATIVO}

Foram realizadas 12 sessões do Conselho Técnico Administrativo, atualmente composto dos Professôres Ildefonso Marques, Presidente, João Alves da Rocha Loures, Laertes de Macedo Munhoz, Ernani Guarita Cartaxo, Nelson Ferreira da Luz, Athos Moraes de Castro Vellozo, Ary Florencio Guimarães, Secretário, Euclides de Queiroz Mesquita, representante dos Docentes-Livres, o acadêmico Otto Luiz Sponholz, e ùltimamente, o acadêmico Luiz Carlos Meinert, Presidentes do Centro Acadêmico "Hugo Simas", e representantes do corpo discente.

De conformidade com a Lei de Diretrizes e Bases e em consonância com a resolução do egrégio Conselho Universitário, tem integrado o douto Conselho Técnico Administrativo o Presidente do Centro Acadêmico "Hugo Simas".

\section{ATIVIDADES ESCOLARES}

AULA INAUGURAL - A aula inaugural da Faculdade de Direite foi proferida no dia $1 .^{\circ}$ de março, às 10 horas, pelo Professor Oscar Martins Gomes, que falou sôbre "Aspectos do Novíssimo Direito Interplanetário".

CONCURSO DE HABILITAÇÃO - Realizaram-se, de 16 a 28 de fevereiro, os exames do Concurso de Habilitação à matrícula na primeira série do curso de bacharelado. 
Foram 257 os candidatos inscritos. Dêsses, foram aprovados 130; reprovados 105; 7 não apresentaram a documentação exigida e 15 não compareceram para prestar as provas regulamentares.

MATRíCULA - Na segunda quinzena de fevereiro, matricularam-se no curso de bacharelado desta Faculdade de Direito:

No $1 .^{\circ}$ ano - 140 alunos;

No $2 .^{\circ}$ ano -128 alunos;

No $3 .^{\circ}$ ano - 127 alunos;

No $4 .^{\circ}$ ano - 106 alunos;

No $5 .^{\circ}$ ano - 80 alunos;

TOTAL ............ 587 alunos.

FREQUENCIA - Durante o ano corrente, constatou-se que não conseguiram os $2 / 3$ de frequência exigidos por lei, em uma ou mais cadeiras das respectivas séries: no $1 .^{\circ}$ ano, 19 alunos; no $2 .^{\circ}$ ano, 21 alunos; no $3 .^{\circ}$ ano, 33 alunos, no $4 .^{\circ}$ ano, 24 alunos, e no $5 .^{\circ}$ ano, 1 aluno, conforme a seguinte especificação por disciplina:

$11^{\circ}$ ano - Introdução à Ciência do Direito, 13 alunos; Economia Política, 17 alunos;

Direito Romano, 12 alunos;

Teoria Geral do Estado, 13 alunos.

$2 .^{\circ}$ ano - Direito Civil, 8 alunos;

Direito Penal, 13 alunos;

Direito Constitucional, 8 alunos;

Ciência das Finanças, 10 alunos.

3. ${ }^{\circ}$ ano - Direito Civil, 14 alunos;

Direito Penal, 12 alunos;

Direito Comercial, 27 alunos;

Direito Internacional Público, 16 alunos;

Direito do Trabalho, 18 alunos.

$4 .^{\circ}$ ano - Direito Civil, 12 alunos;

Direito Judiciário Civil, 12 alunos;

Direito Penal, 20 alunos;

Direito Comercial, 17 alunos;

Medicina Legal, 10 alunos.

5. ${ }^{\circ}$ ano - Direito Judiciário Civil, 1 aluno;

Direito Judiciário Penal, 1 aluno.

$E^{\prime}$ a seguinte a porcentagem dos alunos que não alcançaram $2 / 3$ de frequência:

$$
\begin{aligned}
& \text { No } 1 .^{\circ} \text { ano }-13,6 \% \\
& \text { No } 2 .^{\circ} \text { ano }-16,4 \% \\
& \text { No } 3 .^{\circ} \text { ano }-25,9 \% \\
& \text { No } 4 .^{\circ} \text { ano }-22,6 \% \\
& \text { No } 5 .^{\circ} \text { ano }-1,25 \%
\end{aligned}
$$


Não alcançaram $1 / 4$ de frequência, em uma ou mais cadeiras das respectivas séries, e de consequência não prestarão exames em segunda época (art. 166, c, do Regimento Interno da Faculdade): no $1 .^{\circ}$ ano, 7 alunos; no $2 .^{\circ}$ ano, 13 alunos; no $3 .^{\circ}$ ano, 14 alunos; e no $4 .^{\circ}$ ano, 5 alunos, de acôrdo com a seguinte tabela:

1.` ano - Introdução à Ciência do Direito, 6 alunos; Direito Romano, 6 alunos;

Teoria Geral do Estado, 5 alunos.

2. ano - Direito Civil, 12 alunos;

Direito Penal, 13 alunos;

Direito Constitucional, 7 alunos;

Ciência das Finanças, 6 alunos.

3. ${ }^{\circ}$ ano - Direito Civil, 9 alunos;

Direito Penal, 8 alunos;

Direito Comercial, 11 alunos;

Direito Internacional Público, 9 alunos;

Direito do Trabalho, 8 alunos.

$4 .^{\circ}$ ano - Direito Civil, 3 alunos;

Direito Judiciário Civil, 3 alunos;

Direito Penal, 5 alunos;

Direito Comercial, 1 aluno;

Medicina Legal, 2 alunos.

$E^{\prime}$ a seguinte a porcentagem dos alunos que não alcançaram $1 / 4$ da frequência exigida:

$$
\begin{aligned}
& \text { No } 1 .^{\circ} \text { ano }-5 \% \\
& \text { No } 2 .^{\circ} \text { ano }-10,1 \% \\
& \text { No } 3 .^{\circ} \text { ano }-11 \% \\
& \text { No } 4 .^{\circ} \text { ano }-4,7 \%
\end{aligned}
$$

EXAMES FINAIS - $E^{\prime}$ o seguinte o quadro relativo aos exames finais, prestados em primeira época, no presente ano de 1963:

1. ${ }^{\circ}$ ANO

Introdução à Ciência do Direito

Economia Política

Direito Romano

Teoria Geral do Estado

\section{Aprovados}

45

6

24

11
Reprovados

10

1

5

1

\section{ANO}

Direito Civil

Direito Penal

Direito Constitucional

Ciência das Finanças 
3. ANO

$\begin{array}{lrr}\text { Direito Civil } & 38 & 8 \\ \text { Direito Penal } & 10 & - \\ \text { Direito Comercial } & 37 & 4 \\ \text { Direito Internacional Público } & 64 & 11 \\ \text { Direito do Trabalho } & 56 & 3\end{array}$

4. ${ }^{\circ}$ ANO

Direito Civil

Direito Penal

Direito Judiciário Civil

Direito Comercial

Medicina Legal

$\begin{array}{rr}25 & 10 \\ 3 & - \\ 6 & - \\ 24 & 2 \\ 14 & 1\end{array}$

5. ANO

$\begin{array}{lcc}\text { Direito Civil } & 33 & - \\ \text { Direito Judiciário Civil } & 31 & - \\ \text { Direito Judiciário Penal } & 47 & - \\ \text { Direito Administrativo } & - & - \\ \text { Direito Internacional Privado } & - & -\end{array}$

EXAMES FINAIS EM SEGUNDA EPOCA - Realizaram-se em fevereiro dêste ano os exames de segunda época, referentes ao ano escolar de 1962, com os seguintes resultados:

1. ANO

Introdução à Ciência do Direito Economia Política

Direito Romano

Teoria Geral do Estado

\section{Aprovados Reprovados}

10

7

22

7
5

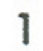

5

2

\section{ANO}

Direito Civil

Direito Penal

Direito Constitucional

Ciência das Finanças

Direito Administrativo

$\begin{array}{rr}23 & 3 \\ 19 & - \\ 7 & 1- \\ 5 & -\end{array}$

3. ANO

Direito Civil

Direito Penal

10

Direito Comercial

Direito Internacional Público

23

Direito do Trabalho

\section{ANO}
Direito Civil
Direito Penal
Direito Judiciário Civil
Direito Comercial
Medicina Legal 
5. ANO

Direito Civil

Direito Judiciário Civil

Direito Judiciário Penal

Direito Administrativo

Direito Internacional Privado

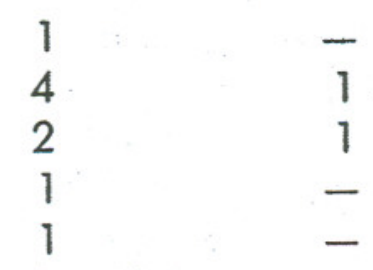

AULAS DADAS - E' o seguinte o quadro de aulas dadas pelos senhores professôres, durante o corrente ano letivo:

1. ano - Introdução à Ciência do Direito, 72 aulas;

Economia Política, 86 aulas;

Direito Romano, 77 aulas;

Teoria Geral do Estado, 69 aulas.

2..$^{\circ}$ ano - Direito Civil, 80 aulas;

Direito Penal, 81 aulas;

Direito Constitucional, 46 aulas;

Ciência das Finanças, 54 aulas.

3. ${ }^{\circ}$ ano - Direito Civil, 73 aulas;

Direito Penal, 75 aulas;

Direito Comercial, 63 aulas;

Direito Internacional Público, 71 aulas;

Direito do Trabalho, 63 aulas.

4. ${ }^{\circ}$ ano - Direito Civil, 69 aulas;

Direito Penal, 89 aulas;

Direito Judiciário Civil, 86 aulas;

Direito Comercial, 83 aulas;

Medicina Legal, 83 aulas.

5. ${ }^{\circ}$ ano - Direito Civil, 45 aulas;

Direito Judiciário Civil, 81 aulas;

Direito Judiciário Penal, 77 aulas;

Direito Administrativo, 49 aulas;

Direito Internacional Privado, 73 aulas.

ALUNOS GRATUITOS - Foram beneficiados com a isenção das taxas escolares, no corrente ano letivo, 6 alunos, sendo 2 na la. série; 1 na $2 a$. série; 1 na $3 a$. série; 1 na $4 a$. série e 1 na $5 a$. série, no curso de bacharelado.

GUIAS DE TRANSFERENCIA - Foram recebidas, durante o ano, 6 guias de transferência sendo 1 na Faculdade Estadual de Direito de Ponta Grossa, 1 da Faculdade Nacional de Direito da Universidade do Brasil, 1 da Faculdade de Direito da Universidade do Recife, 1 da Faculdade de Direito do Triângulo Mineiro, 1 da Faculdade de Direito da Universidade da Bahia e 1 da Faculdade de Direito da Universi dade de Santa Catarina. 
Foram expedidas 10 guias de transferência, sendo: 1 para a Faculdade de Direito de Passo Fundo, Rio Grande do Sul; 5 para a Faculdade Estadual de Direito de Londrina; 1 para a Faculdade de Direito da Pontifícia Universidade Católica do Rio de Janeiro; 1 para a Faculdade de Direito da Universidade de Santa Catarina; 1 para a Faculdade de Direito da Universidade de Minas Gerais; e uma para a Faculdade de Direito da Universidade do Rio Grande do Sul.

COLAÇÃO DE GRAU - No dia 20 do corrente mês de dezembro, no Auditório da Reitoria, colaram grau 67 bacharelandos, componentes da turma "Prof. Oscar Joseph De Plácido e Silva", sendo paraninfo o Professor Gaspar Luiz Lacerda Pinto e patrono o Professor Egas Dirceu Moniz de Aragão.

Durante a cerimônia da colação de grau, presidida pelo Diretor da Faculdade, Prof. Ildefonso Marques, foram entregues os seguintes prêmios:

"Faculdade de Direito da Universidade do Paraná", medalha de ouro, instituido pela Faculdade de Direito da Universidade do Paraná, ao melhor aluno do curso jurídico:

1. - lugar coube ao bacharelando Ivan Ordini Righi;

2. lugar coube ao bacharelando Paulo Antonio Marques Munhoz;

"Assiduidade", medalha de ouro, instituido pela Faculdade de Direito da Universidade do Paraná, ao aluno mais assíduo do curso jurídico:

Coube à bacharelanda Thereza Souza Costa;

"Hugo Simas", medalha de ouro, instituido pelo Centro Acadêmico "Hugo. Simas", ao melhor aluno do curso jurídico:

Coube ao bacharelando Ivan Ordini Righi;

"Ruy Barbosa", Cr\$20.000,00, instituido pela Prefeitura Municipal de Curitiba, ao melhor aluno do curso jurídico:

Coube ao bacharelando Ivan Ordini Righi;

"Des. Vieira Cavalcanti", uma assinatura da revista "Paraná Judiciário" e uma coleção parcial da mesma, instituido pela revista "Paraná Judiciário", ao melhor aluno de Direito Comercial (1961/62).

Coube ao bacharelando Paulo Antonio Marques Munhoz;

"Prof. Enéas Marques dos Santos", instituido pelos professôres Athos Moraes de Castro Vellozo, Ary Florêncio Guimarães e Egas Dirceu Moniz de Aragão, aos melhores alunos das cadeiras de Direito Judiciário Penal e Direito Judiciário Civil, da Faculdade:

1. lugar: medalha de prata, coube ao bacharelando Paulo An. tonio Marques Munhoz;

2. Iugar: medalha de bronze, coube ao bacharelando Ivan Ordini Righi. 
BIBLIOTECA - A Biblioteca da Faculdade de Direito foi inaugurada em 22 de setembro de 1955.

Durante o corrente ano, o movimento de aquisição, inclusive assinaturas de periódicos e doações, totalizou 1.380 volumes, ao custo de $\mathrm{Cr} \$ 2.700 .000,00$.

Em nosso último relatório, referente ao ano de 1962, registramos que o acêrvo da Biblioteca se compunha, inclusive doações, de 29.050 volumes, classificados e fichados. Com as aquisições e doações feitas no presente ano, êsse número alcançou a casa dos 30.420 .

A resenha das aquisições feitas nos últimos 4 anos é a seguinte:

$\begin{array}{lcc}\text { ANO } & \text { VOLUMES } & \text { PREÇO } \\ 1960 & 2.269 & \operatorname{Cr} \$ 1.200 .000,00 \\ 1961 & 2.284 & \operatorname{Cr} \$ 2.000 .000,00 \\ 1962 & 2.826 & \operatorname{Cr} \$ 2.300 .000,00 \\ 1963 & 1.380 & \operatorname{Cr} \$ 2.700 .000,00\end{array}$
sultadas:

$\mathrm{Na}$ Biblioteca Fixa, foi o seguinte o movimento de obras con-

ANO

1960

1961

1962

1963
OBRAS CONSULTADAS

5.237

5.241

3.787

3.280

Os senhores professôres retiraram da Biblioteca, para consulta:

ANO

1960

1961

1962

1963
OBRAS CONSULTADAS

513

722

383

631

Quadro estatístico, por assunto, das obras consultadas no corrente ano letivo:

\section{ASSUNTO}

$$
\begin{aligned}
& 000 \text { - Obras gerais } \\
& 100 \text { - Filosofia } \\
& 200 \text { - Religião } \\
& 300 \text { - Ciências Sociais } \\
& 400 \text { - Filologia } \\
& 600 \text { - Ciências Aplicadas } \\
& 800 \text { - Literatura } \\
& 900 \text { - História, Geografia, Biografia } \\
& \quad \text { Revistas }
\end{aligned}
$$

\section{N. ${ }^{\circ}$ DE CONSULTAS}

13

98

3

3.060 
IDIOMA

Português

Espanhol

Italiano

Francês

Inglês

Latim

\section{N. ${ }^{\circ}$ DE CONSULTAS}

2.500

401

174

185

9

6

TOTAL

3.280

BIBLIOTECA CIRCULANTE - A Biblioteca Circulante da Faculdade de Direito, inaugurada em 21 de maio de 1962, teve o seu Regulamento Interno aprovado em sessão do Conselho Técnico Administrativo de 5 de outubro de 1962.

$\mathrm{E}^{\prime}$ permitido aos alunos a retirada de livros da referida Bibliote. ca, razão pela qual, diminuiu o número de consultas da Biblioteca Fixa. guinte:

O número de inscrições de alunos, no corrente ano, foi o se-

Janeiro -3 ; fevereiro -5 ; março -24 ; abril -38 ; maio -24 ; junho - 49; julho - -; agôsto - 12; setembro - 9; outubro - 10; novembro - 15; dezembro - 4, num total de 193 inscrições.

Obras retiradas pelos alunos, durante o corrente ano:

MESES

Janeiro

Fevereiro

Março

Abril

Maio

Junho

Julho

Agôsto

Setembro

Outubro

Novembro

Dezembro
CIENCIAS SOCIAIS

50

47

128

273

308

512

80

275

248

353

586

135

Total ..... $2 . \overline{995}$

\section{DIVERSOS}

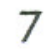

1

13

5

6

6

3

15

8

8

2

4

78

IDIOMA

Português

N. ${ }^{\circ}$ DE CONSULTAS

Espanhol

2.990

Francês 
Assim, o movimento geral de consultas na Biblioteca, durante o ano de 1963, foi de 6.353 consultas.

MOVIMENTO FINANCEIRO - Quanto ao relatório do movimento financeiro das verbas do orçamento de receita e despesa da Universidade do Paraná, referente à Faculdade de Direito, e bem assim, ao movimento da conta patrimonial de Faculdade, e por fim a conta da receita e despesa da Escola Técnica de Comércio, anexa a esta Faculdade, figuram os mesmos nos anexos seguintes, que submeto à aprovação da Congregação.

AGRADECIMENTO - Cumpre-me consignar o meu melhor agradecimento ao Magnífico Reitor da Universidade do Paraná, Prof. Flávio Suplicy de Lacerda, ao Vice-Reitor, Professor José Nicolau dos Santos, aos doutíssimos integrantes do egrégio Conselho Técnico Administrativo e da egrégia Congregação, aos senhores Instrutores, aos estudantes Otto Luiz Sponholz e Luiz Carlos Meinert, dirigentes da luzida classe acadêmica e aos senhores funcionários, pela preciosa colaboração que me emprestaram.

Curitiba, 27 de dezembro de 1963.

ILDEFONSO MARQUES

\section{Diretor}

